\title{
A prospective, randomized Phase II clinical trial to evaluate the effect of combined hyperbaric and normobaric hyperoxia on cerebral metabolism, intracranial pressure, oxygen toxicity, and clinical outcome in severe traumatic brain injury
}

\author{
Clinical article
}

\author{
*Sarah B. Rockswold, M.D., ${ }^{1-3}$ Gaylan L. Rockswold, M.D., Ph.D., ${ }^{3,4}$ David A. Zaun, M.S., 5 \\ and Jiannong LiU, Ph.D. 5 \\ ${ }^{1}$ Department of Physical Medicine and Rehabilitation and ${ }^{3}$ Division of Neurosurgery, Department of Surgery, Hennepin \\ County Medical Center; Departments of ${ }^{2}$ Medicine and Rehabilitation and ${ }^{4}$ Neurosurgery, University of Minnesota, \\ Minneapolis, Minnesota; and ${ }^{5}$ Analytical Services, Chronic Disease Research Group, Minneapolis Medical Research \\ Foundation, Minneapolis, Minnesota
}

\begin{abstract}
Object. Preclinical and clinical investigations indicate that the positive effect of hyperbaric oxygen $\left(\mathrm{HBO}_{2}\right)$ for severe traumatic brain injury (TBI) occurs after rather than during treatment. The brain appears better able to use baseline $\mathrm{O}_{2}$ levels following $\mathrm{HBO}_{2}$ treatments. In this study, the authors evaluate the combination of $\mathrm{HBO}_{2}$ and normobaric hyperoxia $(\mathrm{NBH})$ as a single treatment.

Methods. Forty-two patients who sustained severe TBI (mean Glasgow Coma Scale [GCS] score 5.7) were prospectively randomized within 24 hours of injury to either: 1) combined $\mathrm{HBO}_{2} / \mathrm{NBH}\left(60\right.$ minutes of $\mathrm{HBO}_{2}$ at 1.5 atmospheres absolute [ATA] followed by $\mathrm{NBH}, 3$ hours of $100 \%$ fraction of inspired oxygen $\left[\mathrm{FiO}_{2}\right]$ at $1.0 \mathrm{ATA}$ ) or 2) control, standard care. Treatments occurred once every 24 hours for 3 consecutive days. Intracranial pressure, surrogate markers for cerebral metabolism, and $\mathrm{O}_{2}$ toxicity were monitored. Clinical outcome was assessed at 6 months using the sliding dichotomized Glasgow Outcome Scale (GOS) score. Mixedeffects linear modeling was used to statistically test differences between the treatment and control groups. Functional outcome and mortality rates were compared using chi-square tests.

Results. There were no significant differences in demographic characteristics between the 2 groups. In comparison with values in the control group, brain tissue partial pressure of $\mathrm{O}_{2}\left(\mathrm{PO}_{2}\right)$ levels were significantly increased during and following combined $\mathrm{HBO}_{2} / \mathrm{NBH}$ treatments in both the noninjured and pericontusional brain $(\mathrm{p}<0.0001)$. Microdialysate lactate/pyruvate ratios were significantly decreased in the noninjured brain in the combined $\mathrm{HBO}_{2} / \mathrm{NBH}$ group as compared with controls $(\mathrm{p}<0.0078)$. The combined $\mathrm{HBO}_{2} / \mathrm{NBH}$ group's intracranial pressure values were significantly lower than those of the control group during treatment, and

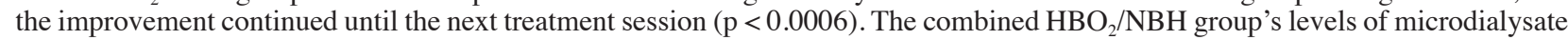
glycerol were significantly lower than those of the control group in both noninjured and pericontusional brain $(\mathrm{p}<0.001)$. The combined $\mathrm{HBO}_{2} / \mathrm{NBH}$ group's level of CSF F2-isoprostane was decreased at 6 hours after treatment as compared with that of controls, but the difference did not quite reach statistical significance $(\mathrm{p}=0.0692)$. There was an absolute $26 \%$ reduction in mortality for the combined $\mathrm{HBO}_{2} / \mathrm{NBH}$ group $(\mathrm{p}=0.048)$ and an absolute $36 \%$ improvement in favorable outcome using the sliding dichotomized $\operatorname{GOS}(\mathrm{p}=0.024)$ as compared with the control group.

Conclusions. In this Phase II clinical trial, in comparison with standard care (control treatment) combined $\mathrm{HBO}_{2} / \mathrm{NBH}$ treatments significantly improved markers of oxidative metabolism in relatively uninjured brain as well as pericontusional tissue, reduced intracranial hypertension, and demonstrated improvement in markers of cerebral toxicity. There was significant reduction in mortality and improved favorable outcome as measured by GOS. The combination of $\mathrm{HBO}_{2}$ and $\mathrm{NBH}$ therapy appears to have potential therapeutic efficacy as compared with the 2 treatments in isolation. Clinical trial registration no.: NCT00170352 (ClinicalTrials.gov). (http://thejns.org/doi/abs/10.3171/2013.2.JNS121468)
\end{abstract}

\section{KEY WORDS • hyperbaric oxygen • normobaric hyperoxia • traumatic brain injury cerebral metabolism • intracranial pressure $\quad$ oxygen toxicity $\quad$ clinical outcome}

Abbreviations used in this paper: ATA = atmospheres absolute; $\mathrm{ATP}=$ adenosine triphosphate; $\mathrm{BAL}=$ bronchial alveolar lavage; $\mathrm{FiO}_{2}=$ fraction of inspired oxygen; GCS = Glasgow Coma Scale; $\mathrm{GOS}=$ Glasgow Outcome Scale; $\mathrm{HBO}_{2}=$ hyperbaric oxygen; $\mathrm{ICP}=$ intracranial pressure; $\mathrm{L} / \mathrm{P}=$ lactate/pyruvate; $\mathrm{MMP}=$ matrix metalloproteinase; $\mathrm{NBH}=$ normobaric hyperoxia; $\mathrm{PaCO}_{2}=$ partial pressure of arterial carbon dioxide; $\mathrm{PaO}_{2}=$ partial pressure of arterial $\mathrm{O}_{2}$; $\mathrm{PEEP}=$ positive end-expiratory pressure $\mathrm{PO}_{2}=$ partial pressure of $\mathrm{O}_{2}$; TBI = traumatic brain injury; TIL = therapeutic intensity level.

* Drs. Sarah B. Rockswold and Gaylan L. Rockswold contributed equally to this work.
$\mathrm{T}$

HE enormous negative social and economic impact of TBI throughout the world cannot be overemphasized. The major issue is premature death and disability both in civilian and military populations. Conservative estimates of the prevalence of long-term disability due to TBI in the United States are well over 3 million people. The economic toll of TBI exceeds $\$ 60$ billion per year. ${ }^{18}$

Our previous investigations of $\mathrm{HBO}_{2}$ in the treatment of severe TBI strongly suggest that the beneficial effect 
demonstrated does not occur during the treatment but in the hours following the treatment. ${ }^{44,45}$ The data suggest that $\mathrm{HBO}_{2}$ enables the brain to use increased $\mathrm{FiO}_{2}$ in the posttreatment period. Experimental investigations also support the concept of using $\mathrm{HBO}_{2}$ followed by continued increased $\mathrm{O}_{2}$ at normobaric pressures as a single treatment. ${ }^{9,65}$ These studies have documented significant improvement in mitochondrial function, ATP production, reduced hippocampus cell loss, and functional recovery following a combined $\mathrm{HBO}_{2} / \mathrm{NBH}$ treatment as compared with NBH alone or control animals. The case for evaluating the combination of $\mathrm{HBO}_{2}$ and $\mathrm{NBH}$ as a single treatment appeared compelling. The 2 treatments in tandem are potentially synergistic.

The goal of this study was to evaluate cerebral metabolism, ICP, potential $\mathrm{O}_{2}$ toxicity, and clinical outcome during a prospective, randomized Phase II clinical trial comparing a combined treatment of $\mathrm{HBO}_{2} / \mathrm{NBH}$ to standard care in patients with severe TBI. This study was a subsequent supplement to a larger prospective, randomized clinical trial. ${ }^{45}$ This report differs from that previously published study in that $\mathrm{O}_{2}$ delivery and cerebral metabolism were studied in the pericontusional areas of some patients and clinical outcome was assessed at 6 months using the GOS; moreover, in the present study, $\mathrm{HBO}_{2}$ and $\mathrm{NBH}$ were evaluated in combination rather than separately.

\section{Methods}

This study was registered with the ClinicalTrials. gov database (http://clinicaltrials.gov), and its registration number is NCT00170352.

Forty-two patients treated for severe TBI at the Hennepin County Medical Center, a Level 1 trauma center, were entered into a prospective randomized Phase II clinical trial to evaluate the mechanisms of action of hyperoxia on cerebral metabolism, ICP, $\mathrm{O}_{2}$ toxicity, and clinical outcome. This study was a subsequent supplement to a larger prospective, randomized clinical trial. ${ }^{45}$ The protocol for this study was approved by the Human Subjects Research Committee at our institution. All patients had sustained severe TBI as defined by a GCS score of 8 or less after resuscitation. This score was determined when no effects from paralytic agents, sedation, alcohol, and/or street drugs were present. Patients were entered into the study within 24 hours of their injury. Patients also were entered into the study if they were admitted to the hospital with a mild or moderate TBI and deteriorated to a GCS score of 8 or less within 48 hours after their injury (2 patients in the combined $\mathrm{HBO}_{2} / \mathrm{NBH}$ group and 3 in the control group). ${ }^{29,43}$ All CT scan scores were II or greater, in conformance with the classification system of the Traumatic Coma Data Bank. ${ }^{28}$ After eligibility and the GCS score were established, informed consent was obtained from the patients' legally authorized representative. Randomization occurred immediately after consent for study enrollment was obtained. Inclusion/exclusion criteria are listed in Table 1. All patients received intensive neurosurgical care closely paralleling that of the Brain Trauma Foundation "Guidelines for the Management of Severe TBI, Third Edition."7 This protocol included stabilization

\section{TABLE 1: Study inclusion and exclusion criteria}

\section{Inclusion Criteria}

all closed-head trauma victims w/ GCS score of 3-8 after resuscitation, w/o effects from paralytics, sedation, alcohol \&/or street drugs

$\mathrm{HBO}_{2}$ treatment to begin w/in 24 hrs after injury

admission to hospital w/ a mild or moderate brain injury \& deterioration w/in 48 hrs

CT scan score $\geq 2$ in accordance $w /$ classification system of Traumatic Coma Data Bank

\begin{tabular}{l} 
Exclusion Criteria \\
bilateral fixed midposition pupils \\
severe pulmonary injury requiring $\mathrm{FiO}_{2}>50 \%$ \&/or PEEP $>10 \mathrm{~cm} \mathrm{H}_{2} \mathrm{O}$ \\
to maintain adequate oxygenation \\
history of severe pulmonary disease (e.g., asthma or chronic obstruc- \\
tion pulmonary disease) \\
fixed coagulopathy \\
pregnancy \\
severe mental retardation or prior severe brain injury or stroke \\
high-velocity penetrating injury to head \\
\hline
\end{tabular}

with early intubation while the patient was in the emergency department, surgical evacuation of significant hematomas, continuous monitoring of ICP, and treatment of ICP greater than $15 \mathrm{~mm} \mathrm{Hg}$. All patients received prophylactic phenytoin sodium. The protocol adhered to the principles set forth in the US Code of Federal Regulations, Title 45, Part 46, Protection of Human Subjects and the World Medical Association Declaration of Helsinki.

This randomized Phase II clinical trial was designed as a 2-treatment comparison: combined $\mathrm{HBO}_{2} / \mathrm{NBH}$ treatment compared with standard care. Twenty patients received the combined $\mathrm{HBO}_{2} / \mathrm{NBH}$ treatment, which consisted of $100 \% \mathrm{FiO}_{2}$ delivered for 60 minutes at 1.5 ATA followed by 3 hours at 1.0 ATA. Standard care was the control treatment, which 22 patients received. The first $\mathrm{O}_{2}$ treatment was administered as soon as the entry criteria were met and the patient's condition was clinically stable. Subsequent treatments were given every 24 hours. Patients received 3 consecutive treatments unless they became brain dead or were consistently able to follow commands. The first 2 patients randomized to the combined $\mathrm{HBO}_{2} /$ $\mathrm{NBH}$ arm were placed in a Class A, 4-lock multiplace chamber (Vacudyne, Inc.), and the next 18 in a 34-inch-diameter Bara-Med XD monoplace chamber (Environmental Tectonics Corp.). Compression to 1.5 ATA occurred at a rate of $1.0 \mathrm{lb} / \mathrm{in}^{2} / \mathrm{min}$ and lasted 17 minutes. The patients were kept at depth for 60 minutes and underwent decompression at the same rate.

Important baseline parameters were maintained between the pretreatment and posttreatment periods. $\mathrm{Pa}-$ tients in the combined $\mathrm{HBO}_{2} / \mathrm{NBH}$ treatment group were first transported to the hyperbaric chamber area, which can essentially function as an ICU. Once they were there, their baseline $\mathrm{PaCO}_{2}, \mathrm{PaO}_{2}, \mathrm{ICP}$, and cerebral perfusion pressure were meticulously reestablished. The $\mathrm{FiO}_{2}$ necessary to achieve a $\mathrm{PaO}_{2}$ in the range of $90-130 \mathrm{~mm} \mathrm{Hg}$ was established. The $\mathrm{PaCO}_{2}$ was kept relatively constant, 
at approximately $35-40 \mathrm{~mm} \mathrm{Hg}$. The Licox catheter brain tissue $\mathrm{PO}_{2}$ microprobe was calibrated in the $\mathrm{HBO}_{2}$ chamber (Integra Neurosciences). The respiratory settings were kept constant for 1 hour to establish a baseline. Subsequently, the $\mathrm{HBO}_{2}$ was administered. The patient was then transported back to the regular ICU where again equilibrium was established. Bilateral myringotomies were performed in all patients in the combined $\mathrm{HBO}_{2} /$ NBH treatment group.

\section{Monitored Variables}

Variables were measured before initiation of therapy and for 24 hours after therapy. There were no significant differences in baseline values between the 2 groups prior to hyperoxia treatments except for bronchial alveolar lavage (BAL) fluid IL-8 levels (see Table 2). Continuously monitored outcome variables included brain tissue $\mathrm{PO}_{2}$, ICP, and microdialysate lactate, glucose, pyruvate, and glycerol levels. The brain tissue $\mathrm{PO}_{2}$ measurements were downloaded into a Dell personal computer. Mean values over each 30-minute interval were calculated, except during $\mathrm{HBO}_{2}$, when mean values were calculated over each 15-minute interval. Microdialysate samples were collected every hour. The recovery rate of the microdialysate was reduced during compression, so samples could not be obtained during the $\mathrm{HBO}_{2}$ sessions, but they were taken during the NBH portion of the hyperoxia treatments. ${ }^{21}$ Intracranial pressure measurements were recorded hourly. Measurements of $\mathrm{O}_{2}$ toxicity, including ventricular CSF F2-isoprostanes and BAL IL-8 and IL-6, were taken before treatment and 6 hours after treatment. All monitored variables were recorded in a database (Access 2003, Microsoft Corporation) and synchronized. However, for each variable measured, some patients had missing data and so were not included in that particular statistical analysis. Differences in the numbers of patients are reflected in the figures. In all cases, the missing number of patients was approximately equivalent in the combined $\mathrm{HBO}_{2} / \mathrm{NBH}$ treatment and control groups. The missing data for brain tissue $\mathrm{PO}_{2}$ and microdialysate levels were attributable to probe malfunction or placement directly into injured tissue such as contusion or hemorrhage. One patient in the combined $\mathrm{HBO}_{2} / \mathrm{NBH}$ group did not have ICP measurements as the ventriculostomy could not be placed because of a bilateral decompressive craniectomy.
The results of the trial allowed a direct comparison of the combined treatment of $\mathrm{HBO}_{2}$ and $\mathrm{NBH}$ with standard care in terms of the treatment efficacy on the surrogate outcome variables as well as the patients' functional outcome and mortality.

\section{Continuous Metabolic Monitoring}

A Licox catheter brain tissue $\mathrm{PO}_{2}$ microprobe was used to measure brain tissue $\mathrm{PO}_{2}$ and temperature (Integra LifeSciences). A CMA-70 microdialysis catheter was used to obtain all microdialysate samples (CMA Microdialysis). This catheter was inserted through the triple lumen bolt, along with the $\mathrm{O}_{2}$ and temperature probes, into the frontal cortex of the brain to the desired depth of 14-24 mm. No data were collected in the first 3 hours to avoid insertion artifacts. Artificial CSF solution was infused through the probes at the rate of $0.3 \mu \mathrm{l} / \mathrm{min}$. Dialysates were collected in outflow vials and frozen at $-80^{\circ}$ C. Lactate, glucose, pyruvate, and glycerol levels from the collected dialysate were measured using an off-line analyzer (CMA 600 Microdialysis Analyzer). The microdialysate $\mathrm{L} / \mathrm{P}$ ratios were calculated as a marker for ischemia and the cellular redox state. Brain tissue $\mathrm{PO}_{2}$ probes and microdialysis catheters were placed in either the right or left frontal lobe, whichever was least damaged. This location represented our "standard or non-injured area" of brain tissue not overtly traumatized. In 9 patients, a second brain tissue $\mathrm{PO}_{2}$ probe and a second microdialysis catheter were placed in a pericontusional area or "traumatic penumbra" tissue. The pericontusional area was defined as the hypodense area around the core of the contusion or hematoma on CT scan..$^{16}$ The position of the brain tissue $\mathrm{PO}_{2}$ probes and the microdialysis catheters were checked by a CT scan as soon as possible after insertion.

\section{Intracranial Pressure}

Global ICP measurements were obtained with a tunneled intraventricular catheter. Any ICP greater than 15 $\mathrm{mm} \mathrm{Hg}$ was treated. This treatment sequentially included mild hyperventilation, CSF drainage, administration of osmotic agents, sedation/administration of paralytic agents, and finally, decompressive craniectomy. Therapeutic intensity level (TIL) scores were recorded with ICP measurements. ${ }^{30}$

TABLE 2: Baseline mean values for combined $\mathrm{HBO}_{2} / \mathrm{NBH}$ and control groups for measured values prior to treatment*

\begin{tabular}{lccc}
\hline \multicolumn{1}{c}{ Parameter } & $\mathrm{HBO}_{2} / \mathrm{NBH}$ & Control & $p$ Value \\
\hline mean brain tissue $\mathrm{PO}_{2}(\mathrm{~mm} \mathrm{Hg})$ & $31.7 \pm 3.6$ & $28.9 \pm 2.7$ & 0.5398 \\
microdialysate lactate $(\mathrm{mmol})$ & $2.12 \pm .25$ & $2.68 \pm 0.2$ & 0.5877 \\
microdialysate L/P ratio & $27.5 \pm 2.4$ & $26.9 \pm 3.8$ & 0.9490 \\
microdialysate glycerol $(\mathrm{mmol})$ & $72.5 \pm 18.6$ & $78.7 \pm 18.6$ & 0.8149 \\
ICP $(\mathrm{mm} \mathrm{Hg})$ & $11.3 \pm 1.4$ & $11.3 \pm 0.9$ & 0.2672 \\
ventricular CSF F2-isoprostane $(\mathrm{pg} / \mathrm{ml})$ & $57.1 \pm 11.4$ & $49.2 \pm 3.9$ & 0.3538 \\
BAL IL-6 $(\mathrm{ng} / \mathrm{ml})$ & $7.37 \pm 3.4$ & $4.37 \pm 1.3$ & 0.2047 \\
BAL IL-8 $(\mathrm{ng} / \mathrm{ml})$ & $188.4 \pm 49.2$ & $41.2 \pm 8.5$ & 0.0258 \\
\hline
\end{tabular}

* Means are given \pm SEMs. 


\section{Oxygen Toxicity Markers}

Bronchial alveolar lavage fluid samples were obtained through the endotracheal tube using sterile technique and routine respiratory care. A suction catheter (Medline Industries) was wedged into a distal lung segment, and 30 $\mathrm{ml}$ of sterile saline $\left(0.9 \% \mathrm{NaCl}, 37^{\circ} \mathrm{C}\right)$ was instilled and aspirated with suction into a sterile specimen collector (Allegiance Healthcare). All samples were chilled at $4^{\circ} \mathrm{C}$ immediately and processed within 15 minutes of collection. Samples were strained through a 60-mesh steel screen to remove mucus and then were centrifuged to remove cells, aliquoted, and frozen at $-80^{\circ} \mathrm{C}$ until assayed for IL-8 and IL-6. The BAL IL-8 and IL-6 concentrations were determined by a commercial enzyme-linked immunosorbent assay kit per the manufacturer's direction (BD Biosciences Pharmingen).

Cerebrospinal fluid samples taken from the buretrol of the ventriculostomy were chilled at $4^{\circ} \mathrm{C}$ immediately and processed within 15 minutes of collection. Samples were centrifuged to remove cells, aliquoted, and frozen at $-80^{\circ} \mathrm{C}$. The CSF F2-isoprostane content was measured using a commercial enzyme immunoassay kit (Cayman Chemical).

\section{Outcome}

The baseline severity-adjusted dichotomized GOS score was used as the primary outcome measure for assessing recovery. At 6 months, a blinded assessment using the structured GOS interview was completed with either the patient or, if the patient was unable to participate, the patient's closest family member or legal guardian. The patient was then assigned to one of 5 categories: 1) good recovery (independent, but minor physical or mental deficits may be present); 2) moderately disabled (independent but disabled); 3) severely disabled (dependent on others); 4) vegetative; or 5) dead. ${ }^{62}$ Patients with enrollment GCS scores of 3 , 4 , or 5 were considered to have a favorable outcome if they achieved a GOS score of 1 (good recovery), 2 (moderate disability), or 3 (severe disability). Patients with enrollment GCS scores of 6,7, or 8 were considered to have a favorable outcome if they achieved a good recovery or moderate disability. The dichotomized GOS score was also evaluated so that all patients had to achieve a good recovery or have only moderate disability to be considered to have a favorable outcome.

\section{Statistical Analysis}

Demographic characteristics as well as functional outcome and mortality rates across groups were compared using chi-square tests. This study was not powered as an outcome study as the primary focus was on cerebral metabolism, ICP, and oxygen toxicity.

The outcome analyses focused on the posttreatment effects because the primary study hypothesis was that the effects of hyperoxia on cerebral metabolism and ICP occur primarily after, not during, treatment. However, to examine the efficacy of $\mathrm{HBO}_{2}$ during the $\mathrm{NBH}$ treatment, test values obtained 1 hour after the $\mathrm{HBO}_{2}$ treatment were analyzed as well. A ratio of in- to pretreatment as well as a ratio of post- to pretreatment values was used to study differences among treatment groups for all tests except those for ICP, for which the difference between pre- and posttreatment values was used because of 0 values. All posttreatment values were obtained after the NBH portion of the combined $\mathrm{HBO}_{2} / \mathrm{NBH}$ treatment.

A mixed-effects linear model with fixed effects of treatment (group), time, day, and the treatment-time interaction (with only the significant variables kept in the final model), random patient effect, and autoregressive covariance matrix was used for testing the treatment effect. Due to the skewness of the in-treatment/pretreatment as well as the posttreatment/pretreatment ratios, natural log transformation was made to all in-treatment/pretreatment and posttreatment/pretreatment ratios. When an overall significant group or time*group interaction effect was found in the models using in-treatment/pretreatment and/ or posttreatment/pretreatment ratios, post hoc orthogonal contrasts were used to determine the between-groups difference at each time point.

The graphs are simply a representation of the raw data, and the conclusions are based on the mixed-effects linear statistical model, which takes into account the longitudinal nature of the data. The treatment effect did not differ between treatment periods, so the data are shown in a binary fashion. In addition, there were no significant time*group interactions, so only the global pre- to posttreatment ratio means are shown.

Statistical significance was set at $\mathrm{p}<0.05$ in all analyses, and SAS version 9.1 (SAS Institute) was used to perform all analyses.

\section{Results}

\section{Demographic and Clinical Characteristics}

Demographic and clinical characteristics, including age, sex, mass lesion evacuations, decompressive craniectomies, Marshall CT scan scores, entry-to-study GCS scores, and episodes of intracranial hypertension were compared between the treatment and control groups (Table $3)$. There were no statistically significant differences ( $p>$ $0.05)$. All but 3 surgeries took place prior to randomization; the 3 exceptions involved 1 patient in the combined $\mathrm{HBO}_{2} / \mathrm{NBH}$ group and 2 patients in the control group, all of whom underwent decompressive craniectomy after the treatment period had begun. Lung injuries such as pulmonary contusions ( 4 in the combined $\mathrm{HBO}_{2} / \mathrm{NBH}$ group and 2 in the control group) and pneumo- or hemothoraces (3 in the combined $\mathrm{HBO}_{2} / \mathrm{NBH}$ group and 3 in the control group) were compared and found to be similar ( $p=0.1045)$. There also were no differences in chest radiograph findings between the 2 groups throughout the treatment period $(\mathrm{p}=$ $0.7512)$. There were no significant between-groups differences in the number or type of polytrauma cases $(p>0.05$, Table 4). There were no statistically significant differences between the number or type of brain lesions (findings of blood, contusion, or bone fracture on $\mathrm{CT}$ ) that the combined $\mathrm{HBO}_{2} / \mathrm{NBH}$ treatment group and the control group sustained ( $\mathrm{p}>0.05$, Table 5).

\section{Cerebral Metabolic Measurements}

In the combined $\mathrm{HBO}_{2} / \mathrm{NBH}$ group, patients' brain 


\section{Hyperbaric and normobaric oxygen in TBI}

TABLE 3: Summary of demographic and clinical characteristics in 42 patients with severe TBI*

\begin{tabular}{lccc}
\hline & & Treatment Group & \\
\cline { 2 - 4 } \multicolumn{1}{c}{ Variable } & $\mathrm{HBO}_{2} / \mathrm{NBH}$ & Control & Total \\
\hline no. of pts & 20 & 22 & 42 \\
M/F ratio & $5: 1$ & $4: 1$ & $11: 3$ \\
average age (yrs) & 33 & 36 & 35 \\
average study-entry GCS score & 5.6 & 6.0 & 5.7 \\
\% w/ mass lesion evacuation & 30 & 27 & 29 \\
\% w/ decompressive craniectomy & 50 & 24 & 36 \\
\% w/ episode of intracranial hypertension & 35 & 45 & 40 \\
Marshall CT scan score (\% of pts) & & & 19 \\
II & 10 & 27 & 40 \\
III & 50 & 32 & 28 \\
V & 30 & 27 & 12 \\
VI & 10 & 14 & \\
\hline
\end{tabular}

* There is no statistically significant difference in any comparison $(p>0.05)$. Abbreviation: $p t s=$ patients.

tissue $\mathrm{PO}_{2}$ in both the noninjured and pericontusional brain rose during the treatment sessions to approximately $600 \%$ of the control group value $(\mathrm{p}<0.0001)$. The mean baseline brain tissue $\mathrm{PO}_{2}$ level in both groups was approximately $30 \pm 4 \mathrm{~mm} \mathrm{Hg}$ in the noninjured brain. During the $\mathrm{HBO}_{2}$ portion of the combined $\mathrm{HBO}_{2} / \mathrm{NBH}$ treatment, the mean brain tissue $\mathrm{PO}_{2}$ level in noninjured brain rose to $221 \pm 20 \mathrm{~mm} \mathrm{Hg}$. In comparison with the control group, the combined $\mathrm{HBO}_{2} / \mathrm{NBH}$ treatment group's mean brain tissue $\mathrm{PO}_{2}$ levels remained higher by approximately $30 \%$ throughout the posttreatment period, but the improvement was only statistically significant for the first 2.5 hours following treatment $(\mathrm{p}<0.0001)$. In the pericontusional brain, the mean brain tissue $\mathrm{PO}_{2}$ levels remained significantly higher in the combined $\mathrm{HBO}_{2} / \mathrm{NBH}$ treatment group than the control group by approximately $20 \%$ throughout the posttreatment period ( $\mathrm{p}<0.0001$ ). Figure 1 shows brain tissue $\mathrm{PO}_{2}$ in relatively noninjured brain with in-treatment and posttreatment/pretreatment ratio means.

TABLE 4: Summary of additional injuries in TBI patients with polytrauma*

\begin{tabular}{lccc}
\hline & \multicolumn{3}{c}{ Treatment Group } \\
\cline { 2 - 4 } \multicolumn{1}{c}{ Variable } & $\begin{array}{c}\mathrm{HBO}_{2} / \mathrm{NBH} \\
(\mathrm{n}=20)\end{array}$ & $\begin{array}{c}\text { Control } \\
(\mathrm{n}=22)\end{array}$ & $\begin{array}{c}\text { Total } \\
(\mathrm{n}=42)\end{array}$ \\
\hline polytrauma (all cases) & $65 \%$ & $64 \%$ & $64 \%$ \\
pelvic fracture & $20 \%$ & $18 \%$ & $19 \%$ \\
spinal fracture & $30 \%$ & $23 \%$ & $26 \%$ \\
abdominal injury & $25 \%$ & $18 \%$ & $21 \%$ \\
extremity fracture & $10 \%$ & $23 \%$ & $17 \%$ \\
facial fracture & $0 \%$ & $9 \%$ & $5 \%$ \\
other† & $15 \%$ & $18 \%$ & $17 \%$ \\
\hline
\end{tabular}

* Patients may have more than one injury. There is no statistically significant between-groups difference for any comparison ( $p>0.05$ ).

$\dagger$ Rib fracture, shoulder dislocation, diaphragmatic injury.
In the $\mathrm{HBO}_{2} / \mathrm{NBH}$ group, the microdialysate levels of lactate in the pericontusional brain significantly decreased below the control group levels by approximately $14 \%$ during the treatment $(\mathrm{p}=0.0003)$ and for 12 hours posttreatment $(\mathrm{p}=0.0193)$. There was no significant change in the noninjured brain. Figure 2 shows microdialysate lactate in pericontusional brain with intreatment and posttreatment/pretreatment ratio means.

The $\mathrm{L} / \mathrm{P}$ ratio of microdialysate in the noninjured brain was significantly decreased both during treatment $(\mathrm{p}=0.0157)$ and for the entire posttreatment period by approximately $5 \%$ for the combined $\mathrm{HBO}_{2} / \mathrm{NBH}$ groups in comparison with the control group $(\mathrm{p}=0.0078)$. The combined $\mathrm{HBO}_{2} / \mathrm{NBH}$ group's dialysate $\mathrm{L} / \mathrm{P}$ ratio tended to stay below that of the control group throughout the posttreatment period in the pericontusional brain, but this difference did not reach statistical significance. Figure 3 shows microdialysate $\mathrm{L} / \mathrm{P}$ ratios with posttreatment/pretreatment ratio means.

TABLE 5: Summary of brain lesions*

\begin{tabular}{lccc}
\hline & \multicolumn{3}{c}{ Treatment Group } \\
\cline { 2 - 4 } \multicolumn{1}{c}{ Variable } & $\begin{array}{c}\mathrm{HBO}_{2} / \mathrm{NBH} \\
(\mathrm{n}=20)\end{array}$ & $\begin{array}{c}\text { Control } \\
(\mathrm{n}=22)\end{array}$ & $\begin{array}{c}\text { Total } \\
(\mathrm{n}=42)\end{array}$ \\
\hline total w/ brain lesions & $95 \%$ & $86 \%$ & $90 \%$ \\
contusion & $55 \%$ & $41 \%$ & $48 \%$ \\
subdural hematoma & $30 \%$ & $41 \%$ & $36 \%$ \\
epidural hematoma & $15 \%$ & $9 \%$ & $12 \%$ \\
subarachnoid hemorrhage & $35 \%$ & $32 \%$ & $33 \%$ \\
intracerebral hemorrhage & $30 \%$ & $18 \%$ & $24 \%$ \\
diffuse axonal injury & $30 \%$ & $27 \%$ & $29 \%$ \\
intraventricular hemorrhage & $15 \%$ & $9 \%$ & $12 \%$ \\
skull fracture & $15 \%$ & $14 \%$ & $14 \%$ \\
\hline
\end{tabular}

* Values represent percentages of patients with the specified lesion. Some patients had more than one lesion. There was no statistically significant between-groups difference for any comparison ( $p>0.05)$. 


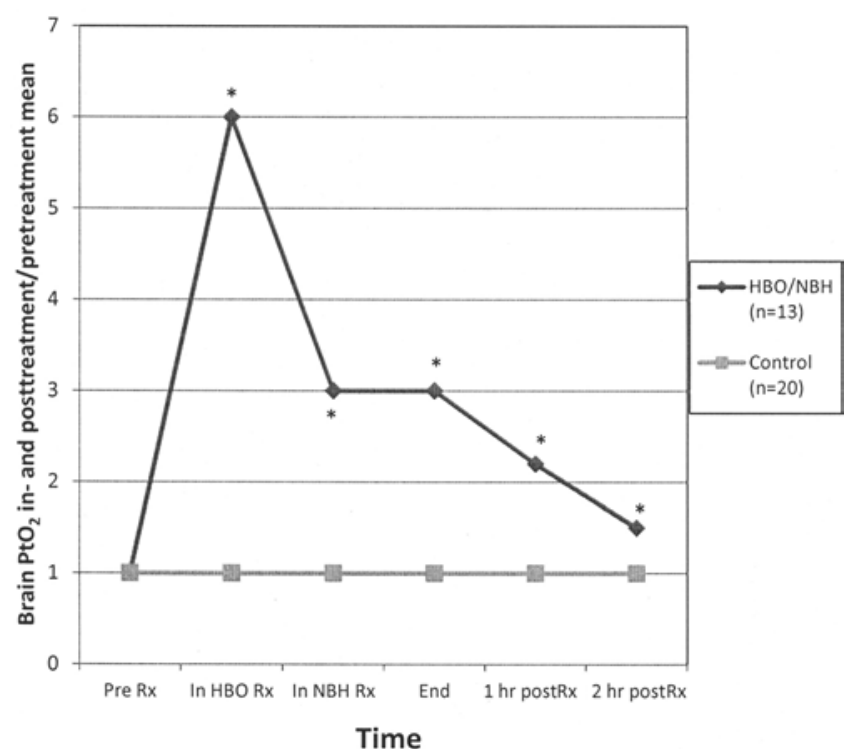

Fig. 1. Graph showing brain tissue $\mathrm{PO}_{2}$ with both in-treatment/ pretreatment and posttreatment/pretreatment ratio means. A value > 1 indicates the in- or posttreatment value is greater than the pretreatment value, and a value $<1$ indicates the in- or posttreatment value is less than the pretreatment value. The graph also depicts the overall comparison of changes among the treatment arms. In comparison with the control group, there was an increase of $\sim 600 \%$ in brain tissue $\mathrm{PO}_{2}$ during the $\mathrm{HBO}_{2}$ portion of the treatment. During the $\mathrm{NBH}$ portion of the treatment, the brain tissue $\mathrm{PO}_{2}$ remained $300 \%$ higher than in the control group until the end of treatment. For 2.5 hours after the combined $\mathrm{HBO}_{2} / \mathrm{NBH}$ treatment, the brain tissue $\mathrm{PO}_{2}$ remained significantly higher than that in the control group by $\sim 50 \%$. ${ }^{*} p<0.0001$ in comparison with the control group. Significance is based on the mixed-effects linear model. $\mathrm{Rx}=$ treatment.

There were no significant differences in the levels of microdialysate glucose in either noninjured or pericontusional brain when the combined $\mathrm{HBO}_{2} / \mathrm{NBH}$ treatment and control groups were compared.

\section{Intracranial Pressure}

The ICP in the combined $\mathrm{HBO}_{2} / \mathrm{NBH}$ group was significantly lower than that of the control group during the $\mathrm{O}_{2}$ treatment $(\mathrm{p}<0.0003)$, and the improvement continued until the next treatment session $(\mathrm{p}<0.0006)$. Patients who started with an ICP greater than $15 \mathrm{~mm}$ $\mathrm{Hg}$ before treatment showed the largest decrease $(\mathrm{p}=$ 0.0019). Figure 4 shows the mean difference of ICP from pretreatment to posttreatment for this patient subgroup. The posttreatment effect was the same for all 3 days. The TIL score was decreased significantly from pretreatment to posttreatment for patients in the combined $\mathrm{HBO}_{2} / \mathrm{NBH}$ group as compared with the control patients $(\mathrm{p}<0.0001)$.

\section{Oxygen Toxicity}

The combined $\mathrm{HBO}_{2} / \mathrm{NBH}$ group's levels of microdialysate glycerol were significantly decreased in comparison with those of the control group in both the noninjured and pericontusional brain $(\mathrm{p}<0.001)$. The combined $\mathrm{HBO}_{2} / \mathrm{NBH}$ group's levels of CSF F2-isoprostane were decreased by approximately $10 \%$ after treatment in comparison with the control group and this decrease almost

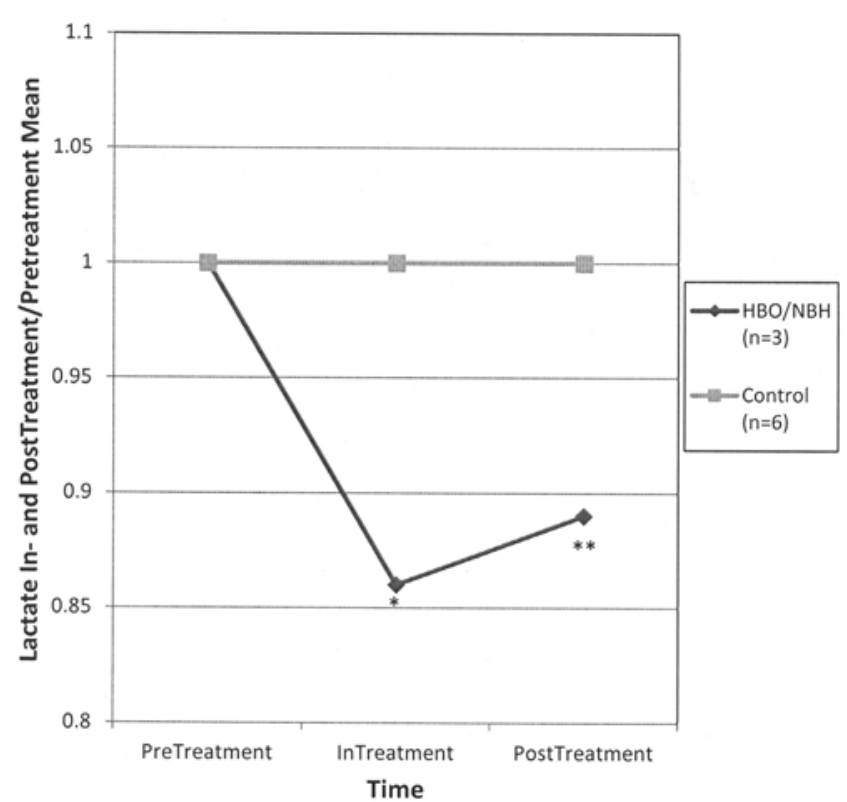

Fig. 2. Graph showing microdialysate lactate in pericontusional brain with both in-treatment/pretreatment and posttreatment/pretreatment ratio means. A value $>1$ indicates the in- or posttreatment value is greater than the pretreatment value, and a value $<1$ indicates the in- or posttreatment value is less than the pretreatment value. This figure also depicts the overall comparison of change between the treatment arms. In patients in the combined $\mathrm{HBO}_{2} / \mathrm{NBH}$ group, microdialysate lactate was decreased by $14 \%$ during the treatment and by $6 \%$ for 12 hours after the treatment in comparison with control group levels. As a significant time* group interaction was not found in the statistical model, only the global pre- to posttreatment ratio means are shown. ${ }^{*} p=0.0003$ and ${ }^{* *} p=0.0193$ in comparison with the control group. Significance is based on the mixed-effects linear model.

reached statistical significance $(\mathrm{p}=0.0692)$. The posttreatment BAL levels of IL-6 and IL-8 cytokines in the $\mathrm{HBO}_{2} / \mathrm{NBH}$ group did not significantly differ from levels in the control group.

One patient in the combined $\mathrm{HBO}_{2} / \mathrm{NBH}$ group had his treatment stopped as a result of increased baseline $\mathrm{FiO}_{2}$ requirements and chest radiograph changes. There was no increased incidence of pneumonia, $\mathrm{FiO}_{2}$ requirement of $50 \%$ of more, or PEEP $>10 \mathrm{~cm} \mathrm{H}_{2} \mathrm{O}$ for the combined $\mathrm{HBO}_{2} / \mathrm{NBH}$ group as compared with the control group.

\section{Clinical Outcome}

One patient from the combined $\mathrm{HBO}_{2} / \mathrm{NBH}$ group and one patient from the control group were lost to follow-up at 6 months; therefore the 6-month outcomes are based on 19 patients in the combined $\mathrm{HBO}_{2} / \mathrm{NBH}$ group and 21 control patients, for a total of 40 patients.

The mortality rate was $16 \%$ for the combined $\mathrm{HBO}_{2} /$ $\mathrm{NBH}$ group as compared with $42 \%$ for the control group. This $26 \%$ reduction (absolute percentage) in mortality for the combined $\mathrm{HBO}_{2} / \mathrm{NBH}$ group as compared with the control group was statistically significant $(\mathrm{p}=0.0482)$.

The statistical analysis also showed that $8(38 \%)$ of the 21 patients in the control group and 14 (74\%) of the 19 patients in the combined $\mathrm{HBO}_{2} / \mathrm{NBH}$ group had a favorable outcome based on the sliding dichotomized GOS. 


\section{Hyperbaric and normobaric oxygen in TBI}

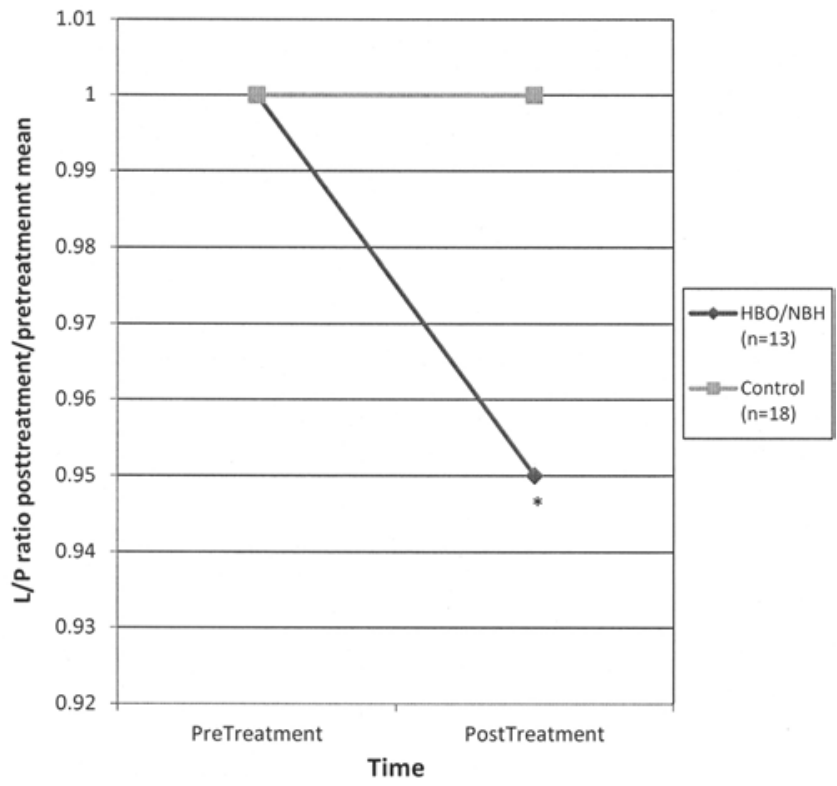

FIG. 3. Graph showing microdialysate L/P ratio in "uninjured" brain with posttreatment/pretreatment ratio means. A value $>1$ indicates the posttreatment value is greater than the pretreatment value, and a value $<1$ indicates the posttreatment value is less than the pretreatment value. This figure also depicts the overall comparison of change between the treatment arms. Posttreatment microdialysate L/P ratios were decreased by $5 \%$ for patients in the $\mathrm{HBO}_{2} / \mathrm{NBH}$ group in comparison with control group levels. As a significant time*group interaction was not found in the statistical model, only the global pre- to in-treatment and the pre- to posttreatment ratio means are shown. ${ }^{*} p=0.0078$ in comparison with the control group. Significance is based on the mixedeffects linear model.

This difference represents an absolute $36 \%$ improvement in favorable outcome and is statistically significant $(\mathrm{p}=$ 0.0239). Based on the dichotomized GOS, 7 (33\%) of 21 patients in the control group and $11(58 \%)$ of the 19 patients in the combined $\mathrm{HBO}_{2} / \mathrm{NBH}$ group had a favorable outcome. This is a $25 \%$ absolute improvement, which almost reached statistical significance $(p=0.077)$.

\section{Discussion}

This is the first report on a prospective, randomized Phase II clinical trial combining $\mathrm{HBO}_{2}$ and $\mathrm{NBH}$ as a single treatment and comparing its effect in terms of surrogate markers of oxidative metabolism, ICP, and $\mathrm{O}_{2}$ toxicity as well as clinical outcome to results in a control group of patients treated with standard care. In addition, the effect of the treatment on cerebral metabolism was studied in both relatively noninjured brain and pericontusional brain tissue. The perilesional area or "traumatic penumbra" has biochemical signs of cerebral energy failure and cell membrane degradation with the capacity to regain a normal metabolic pattern. ${ }^{51}$ There is a significant difference between the energy metabolism of pericontusional tissue and that of relatively noninjured brain tissue in the same patients. ${ }^{16}$ Cerebral energy metabolism is severely decreased in the pericontusional area while being much closer to normal outside of this zone. Combined $\mathrm{HBO}_{2} /$ NBH treatment appears effective in improving cerebral

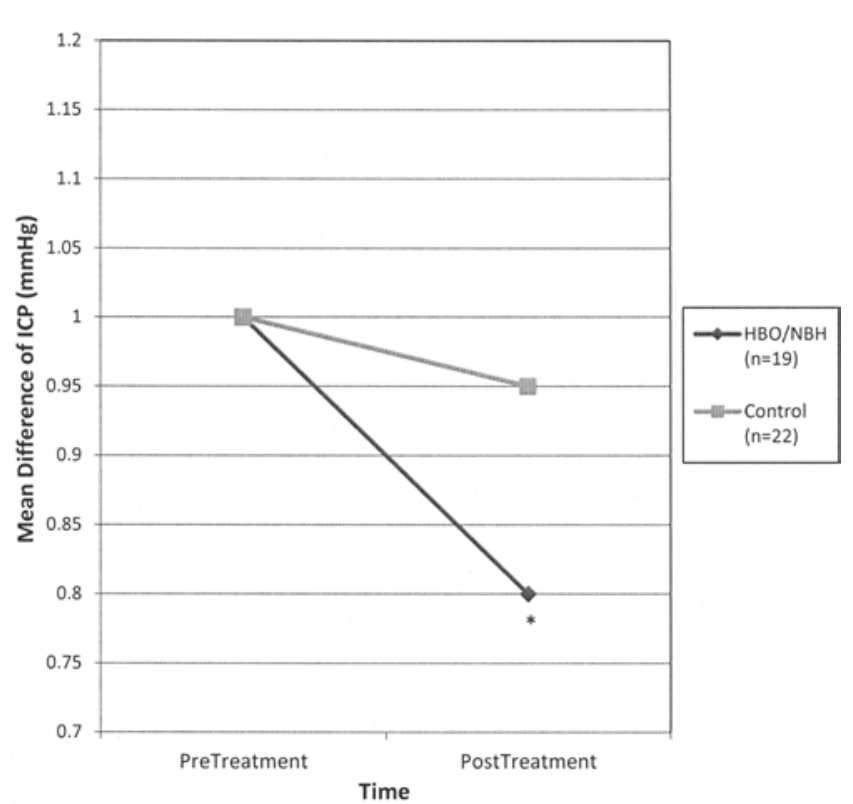

Fig. 4. Graph showing the mean pre- to posttreatment difference in ICP resulting from the statistical model when ICP was greater than 15 $\mathrm{mm} \mathrm{Hg}$ before treatment. The difference in pre- to posttreatment values was used for ICP instead of the ratio of pretreatment values to posttreatment values because of 0 values. This figure also depicts the overall comparison of change between the treatment arms. The combined $\mathrm{HBO}_{2} / \mathrm{NBH}$ group's difference in ICP from pre- to posttreatment was significantly lower than the control group when ICP was greater than $15 \mathrm{~mm} \mathrm{Hg}$ prior to treatment. As a significant time*group interaction was not found in the statistical model, only overall pre- to posttreatment mean differences are shown. ${ }^{*} p=0.0019$ in comparison with the control group. Significance is based on the mixed-effects linear model.

metabolism in both areas of the traumatically injured brain. In addition, the combination of $\mathrm{HBO}_{2}$ and $\mathrm{NBH}$ therapy appears to have increased therapeutic efficacy as compared with the 2 treatments in isolation.

\section{Mechanism of $\mathrm{HBO}_{2}$}

Hyperbaric $\mathrm{O}_{2}$ therapy appears to have several protective mechanisms of action in severe TBI, likely increasing its potential effectiveness. These mechanisms have been demonstrated in both experimental and clinical investigations and include improved oxidative metabolism and mitochondrial function and reductions in intracranial hypertension, apoptosis, neuroinflammation, and free radical-mediated damage. . $38,39,41,44-46,50,52,58-61,65$ The results of the present randomized clinical trial help to support these findings.

Reduced cerebral blood flow is particularly critical in decreasing substrate delivery in the first 24 hours following severe TBI..$^{5,6,57}$ Studies of cerebral blood flow have revealed a pericontusional zone of low blood flow, which often corresponds to the hypodensity seen on CT scans. ${ }^{20}$ In addition, diffusion barriers reduce cellular delivery of $\mathrm{O}_{2}$ following TBI and decrease the ability of the brain to increase $\mathrm{O}_{2}$ extraction in response to hypoperfusion. ${ }^{31}$ The phenomenon is particularly operative in pericontusional areas. Studies have shown that local brain tissue $\mathrm{PO}_{2}$ levels are significantly correlated with ischemia and outcome..$^{54,55}$ Hyperbaric $\mathrm{O}_{2}$ therapy clearly leads to 
a remarkable increase in the amount of $\mathrm{O}_{2}$ delivered to relatively uninjured brain tissue in patients with TBI. ${ }^{45}$ The present study documents that $\mathrm{O}_{2}$ delivery is also significantly increased to pericontusional areas under hyperbaric conditions.

Our previous investigations of $\mathrm{HBO}_{2}$ in the treatment of severe TBI support the theory that the combination of $\mathrm{HBO}_{2}$ and $\mathrm{NBH}$ therapy potentially has a synergistic effect. ${ }^{44,45}$ During those studies, markers of cerebral metabolism such as the cerebral metabolic rate of $\mathrm{O}_{2}$, microdialysate lactate, and microdialysate $\mathrm{L} / \mathrm{P}$ ratio did not improve during the actual $\mathrm{HBO}_{2}$ treatment but did improve during the next 6-24 hours following $\mathrm{HBO}_{2}$ treatment. When the combined $\mathrm{HBO}_{2} / \mathrm{NBH}$ treatment paradigm was used, the markers for cerebral metabolism, ICP, and oxygen toxicity improved in-treatment, especially in the pericontusional brain. This improvement is likely secondary to the fact that the in-treatment measurements were taken 1 hour after the $\mathrm{HBO}_{2}$ treatment, while the patients were still receiving NBH. The data suggest that $\mathrm{HBO}_{2}$ enables the brain to use increased $\mathrm{FiO}_{2}$ in the posttreatment period. Experimental investigations also support the concept of using $\mathrm{HBO}_{2}$ followed by continued increased $\mathrm{O}_{2}$ at normobaric pressures as a single treatment. ${ }^{9}$ Daugherty et al., ${ }^{9}$ in a lateral fluid percussion TBI rat model with 1 hour of $\mathrm{HBO}_{2}$ treatment at 1.5 ATA followed by 3 hours of NBH, have documented significant improvement in mitochondrial function as measured by redox potential at the completion of the 4 hours of treatment but not at completion of 1 hour of $\mathrm{HBO}_{2}$. These data indicate that mitochondrial function is depressed after TBI but there is a potential for mitochondrial functional recovery and that the combination of $\mathrm{HBO}_{2}$ and $\mathrm{NBH}$ can enhance this recovery. In addition, another experimental study, using the same treatment paradigm, showed that elevated brain tissue $\mathrm{O}_{2}$ favorably influences the binding of $\mathrm{O}_{2}$ in the mitochondrial redox enzyme system leading to significantly reduced cell loss in the CA2-3 region of the hippocampus and improved mitochondrial function and ATP production. ${ }^{65} \mathrm{~A}$ significant improvement in functional recovery as measured by a Morris water maze test also was shown. This effect was not seen in the NBHtreated or control animals. ${ }^{65}$ The results of these studies corroborate the findings that $\mathrm{HBO}_{2}$ used in combination with NBH enhances cellular metabolism by increasing intracellular $\mathrm{O}_{2}$ levels, thereby improving mitochondrial function, which results in enhanced $\mathrm{O}_{2}$ utilization posttreatment.

Further experimental studies have found that $\mathrm{HBO}_{2}$ restores the loss of the mitochondrial transmembrane potential and that the reduction of apoptotic cell death mediated by $\mathrm{HBO}_{2}$ is achieved by a mitochondrial protective effect. $^{39,50}$ The investigators theorize that the increased intracellular $\mathrm{O}_{2}$ bioavailability resulting from $\mathrm{HBO}_{2}$ may contribute to the preservation of mitochondrial integrity and reduce the activation of the mitochondrial pathway of apoptosis. Clinical trials have shown increased global $\mathrm{O}_{2}$ consumption lasting for at least 6 hours after $\mathrm{HBO}_{2}$ treatment. ${ }^{44,45}$ This increase appears to be secondary to improved mitochondrial function. In addition, the effect is seen for at least 5 days postinjury in human TBI pa- tients treated with $\mathrm{HBO}_{2}$. Thus, $\mathrm{HBO}_{2}$ improves oxidative metabolism during the period of prolonged posttrauma hypometabolism.

Experimental studies have shown that energy failure after trauma in the region of a contusion activates monovalent cation channels in penumbral capillary endothelial cells resulting in capillary fragmentation allowing extravasation of blood and progressive hemorrhage associated with worse clinical outcomes. ${ }^{48,49}$ Hyperbaric $\mathrm{O}_{2}$ has decreased the size and the amount of brain destruction in a cerebral contusion rat model. ${ }^{38,58}$ The present study documents that with improved brain tissue $\mathrm{O}_{2}$ delivery to pericontusional areas, markers of cerebral metabolism improve. Improved energy production would prevent the activation of monovalent cation channels in penumbra capillary endothelial cells, providing a mechanistic rationale for the observation that $\mathrm{HBO}_{2}$ reduces the size of hemorrhagic contusions.

Acute inflammation in the perilesional area, while important to the repair process, contributes to secondary neuronal death. ${ }^{8,64}$ Neutrophils contribute to secondary injury by causing microvascular occlusion, releasing free $\mathrm{O}_{2}$ radicals, proteolytic enzymes, and proinflammatory cytokines. ${ }^{8,25,59}$ Matrix metalloproteinases are a group of enzymes that have been demonstrated to be upregulated in experimental TBI. Neutrophils are the primary source of MMPs which, in turn, contribute to brain damage. The effect of $\mathrm{HBO}_{2}$ on neuroinflammation and on the expression of MMP-9 was studied in a cortical contusion rat model. ${ }^{59}$ Neutrophils were revealed by myeloperoxidase staining, and immunohistochemical staining for MMP-9 was performed. The $\mathrm{HBO}_{2}$-treated group had a significant decrease in neutrophilic inflammatory infiltration compared with the control group. The expression of MMP-9 also was significantly lower in the $\mathrm{HBO}_{2}$ group. These results demonstrated that $\mathrm{HBO}_{2}$ decreased the extent of secondary cell death in reactive neuroinflammation in a cortical contusion TBI model compared with controls. Decline of MMP-9 expression after $\mathrm{HBO}_{2}$ may also contribute to protection of brain tissue in the perilesional area.

\section{Oxygen Toxicity}

As in previous clinical trials performed at our institution, ${ }^{41,44,45}$ there were no signs of cerebral or pulmonary $\mathrm{O}_{2}$ toxicity in the present trial. Brain tissue is especially vulnerable to lipid peroxidation because of its high rate of $\mathrm{O}_{2}$ consumption and higher content of phospholipids..$^{12,13,23}$ Cerebrospinal fluid F2-isoprostanes are a unique series of prostaglandin-like compounds formed in vivo from the free radical-catalyzed peroxidation of arachidonic acid and have been used to assess peroxidation in patients with severe TBI. ${ }^{3,4,17,35}$ Glycerol is an end product of phospholipid degradation in neural tissue cell membranes and is a marker of cell damage whether caused by $\mathrm{O}_{2}$ toxicity via free radical formation and lipid peroxidation or secondarily from ischemia. ${ }^{16,19,32}$ Levels of CSF F2-isoprostanes as well as microdialysate glycerol were significantly decreased following combined $\mathrm{HBO}_{2} / \mathrm{NBH}$ treatment. These findings may not only signify that there were no signs of $\mathrm{O}_{2}$ toxicity from the combined $\mathrm{HBO}_{2} / \mathrm{NBH}$ treatment, but, in 
fact, that there was a protective effect against neuroinflammation and free radical-mediated damage.

The lung is the organ most commonly damaged by hyperoxia, since $\mathrm{O}_{2}$ tension in the surface area exposed to $\mathrm{O}_{2}$ in the lungs is substantially higher than in other tissues. ${ }^{26}$ When the inhaled $\mathrm{O}_{2}$ exceeds the protective capacity of antioxidants present in the lungs, acute pulmonary pneumonitis associated with the release of proinflammatory cytokines by alveolar macrophages, specifically IL-8 and IL-6, develops. ${ }^{10,11}$ The amount of these proinflammatory cytokines in the BAL is associated with acute lung injury and pulmonary infection similar to acute respiratory distress syndrome..$^{15,36}$ In the combined $\mathrm{HBO}_{2} / \mathrm{NBH}$ group, patients' BAL levels of IL-6 and IL-8 cytokines did not significantly differ posttreatment from the control group levels. Correspondingly, there was no increased incidence of pneumonia, $\mathrm{FiO}_{2}$ requirements greater than $50 \%$, or PEEP $>10 \mathrm{~cm} \mathrm{H}_{2} \mathrm{O}$ compared with the control group.

\section{Intracranial Pressure}

Intracranial hypertension is the major cause of deterioration and death in the 1st week following severe TBI. ${ }^{24,37}$ Again, in this smaller trial, intracranial hypertension was significantly reduced by the combined $\mathrm{HBO}_{2} /$ $\mathrm{NBH}$ treatment and that improvement continued until the next treatment session. The TIL score (used to assess the aggressiveness of intracranial hypertension) was correspondingly reduced.

\section{Clinical Outcome}

The clinical outcome of the combined $\mathrm{HBO}_{2} / \mathrm{NBH}$ treatment was significantly improved at 6 months compared with controls in this relatively small group of patients. There was an absolute $26 \%$ reduction in mortality, as well as a $36 \%$ improvement in favorable outcome using the sliding dichotomized GOS and a $25 \%$ improvement using the dichotomized GOS. This outcome is significantly better than our prior experience using $\mathrm{HBO}_{2}$ as a single treatment or reports from the literature using $\mathrm{NBH} .{ }^{41,53}$ This improvement in clinical outcome may be due to the synergistic effect of combining $\mathrm{HBO}_{2}$ and $\mathrm{NBH}$ treatments. There was significant improvement in markers of cerebral metabolism and oxygen toxicity as well as ICP during the NBH portion of the combined $\mathrm{HBO}_{2} / \mathrm{NBH}$ treatment. The combined $\mathrm{HBO}_{2} / \mathrm{NBH}$ treatment also significantly improved markers of cerebral metabolism in pericontusional brain tissue as well as "normal" areas posttreatment for several hours as compared with values in the control group. Normobaric hyperoxia following an $\mathrm{HBO}_{2}$ treatment increases the baseline $\mathrm{O}_{2}$ available for mitochondria. The continued increased $\mathrm{O}_{2}$ bioavailability enhances the effect of $\mathrm{HBO}_{2}$ treatment. There have been several studies in the literature that show that improvement in markers of cerebral metabolism and ICP correlate with clinical outcome. ${ }^{14,24,27,33,34,40,47,55}$

In addition to improving cerebral metabolism and ICP, the combined $\mathrm{HBO}_{2} / \mathrm{NBH}$ treatment significantly improved markers of cerebral oxygen toxicity. It is possible that the increased intracellular $\mathrm{O}_{2}$ bioavailability resulting from the combined $\mathrm{HBO}_{2} / \mathrm{NBH}$ treatment may result in the neuroprotection of mitochondrial integrity and reduce the activation of the mitochondrial pathway of apoptosis, and the treatment may reduce free radical-mediated damage as shown in experimental studies. ${ }^{38,39,50,58-61}$ This neuroprotective action of the combined $\mathrm{HBO}_{2} / \mathrm{NBH}$ treatment could lead to the preservation of viable but nonfunctioning mitochondria, which would in turn improve clinical outcome.

A major limitation of the clinical outcome portion of this study is the relatively small number of patients. This trial was not designed or powered to be an outcome study, as the primary focus was on cerebral metabolism, ICP, and oxygen toxicity. Therefore, the outcome results need to be interpreted with caution. However, they point toward the need for a Phase III trial to determine if the combined $\mathrm{HBO}_{2} / \mathrm{NBH}$ treatment could become a significant treatment for patients suffering a severe TBI.

\section{Statistical Methods}

Mixed-effects models, such as those used here and accomplished using the restricted maximum likelihood technique, are highly recommended for analyses in which data are obtained repeatedly but not necessarily at regular or identical times from a cohort of study participants. ${ }^{56}$ Vespa et al..$^{56}$ have stated that mixed-effects models should be used by all researchers studying interdependent serial physiological data. The mixed-effects model controls for the interrelatedness of sequential hourly values within each patient. These models take into account the differences in group sizes and correct for differences in pretreatment values (such as the difference in BAL IL-8 levels) in the calculation of significance.

\section{Generalizability of the Treatment Protocol}

Safe treatment of severe TBI patients with $\mathrm{HBO}_{2}$ requires institutional expertise in the management of severe TBI as well as in critical care hyperbaric medicine. ${ }^{21,42}$ The $\mathrm{HBO}_{2}$ chamber and its environment must become an extension of the ICU to allow safe care of the patient with severe TBI. The expertise of appropriate personnel must be as readily available in the $\mathrm{HBO}_{2}$ environment as it is in the ICU. A monoplace chamber has a relatively small physical space footprint and can be incorporated in or placed adjacent to a critical care support area..$^{45}$ The delivery of $\mathrm{HBO}_{2}$ treatments is relatively labor intensive. It requires transport of the patient to and from the chamber, and proximity of the $\mathrm{HBO}_{2}$ chamber to the ICU minimizes transportation time. Monitoring of the ventilatory status of the patient with severe TBI during transport is critical and includes pulse oximetry and portable end-tidal $\mathrm{CO}_{2}$ monitoring. The monoplace chamber has to be specifically designed to adequately monitor the patient and administer appropriate fluids and medications during the treatment. ${ }^{21}$ Intermittent $\mathrm{HBO}_{2}$ treatments at 1.5 ATA for 60 minutes have resulted in a very low incidence of complications, all of which were reversible. When a monoplace chamber is used, the patient is physically isolated from health care providers, but the chamber can be decompressed in approximately 2 minutes and rapid access to the patient achieved. Our institution has delivered 1984 
$\mathrm{HBO}_{2}$ treatments in 3 prospective clinical studies, and an emergency decompression has never been required. ${ }^{41,44,45}$ If a proper treatment paradigm is maintained, our experience documents that $\mathrm{HBO}_{2}$ treatment can be safely delivered to patients with severe TBI in monoplace as well as multiplace chambers.

\section{Blast Injuries and $\mathrm{HBO}_{2}$}

Blast injuries to the brain represent a spectrum of severity similar to traditional TBI. Armonda and other investigators have documented that the severe injuries are characterized by edema, vasospasm, and intracranial hemorrhage. ${ }^{1,2}$ In severe cases the onset of edema has been rapid and life threatening, requiring emergent decompressive craniectomy. Vasospasm of the internal carotid and anterior cerebral arteries is frequently related to intracranial hemorrhage resulting from penetrating fragments. To the authors' knowledge, no investigations using $\mathrm{HBO}_{2}$ have been applied to this type of injury. However, the $\mathrm{HBO}_{2}$ neuroprotective mechanisms discussed earlier in preclinical and clinical investigations of severe TBI could well be beneficial to patients with severe explosive blast brain injuries. There have been investigations of $\mathrm{HBO}_{2}$ therapy for blast-induced postconcussion syndrome and posttraumatic stress disorder. ${ }^{22}$ The patients experienced their injuries at least 12 months prior to $\mathrm{HBO}_{2}$ treatment. The preliminary report by Harch et al. ${ }^{22}$ suggests that $\mathrm{HBO}_{2}$ should be studied in a larger catchment of patients. The mechanism of action of $\mathrm{HBO}_{2}$ in this setting has not been clearly delineated. It is hypothesized that the potential improvement in neurological function relates to improved cerebral blood flow, particularly to the hippocampus. ${ }^{2,63}$

In summary, the treatment of blast-induced TBI with $\mathrm{HBO}_{2}$ is at a preliminary stage but deserves further investigation.

\section{Conclusions}

Data in this study can be summarized by the following key points: 1) The combined $\mathrm{HBO}_{2} / \mathrm{NBH}$ treatment significantly improved markers of oxidative cerebral metabolism in relatively uninjured brain tissue but, importantly, also in pericontusional tissue. 2) The combined $\mathrm{HBO}_{2} / \mathrm{NBH}$ treatment reduced intracranial hypertension and thereby decreased the therapeutic intensity of treatment of intracranial hypertension. 3) There was no evidence of $\mathrm{O}_{2}$ toxicity either in the brain or lungs, and there was actual demonstrated improvement in markers of cerebral toxicity. 4) Combining $\mathrm{HBO}_{2}$ and $\mathrm{NBH}$ into a single treatment potentially has a synergistic therapeutic effect. 5) The combined $\mathrm{HBO}_{2} / \mathrm{NBH}$ treatment reduced mortality and improved favorable outcome as measured by the GOS at 6 months. This improvement was significantly better than past clinical outcomes observed with either of the treatments used separately. The clinical outcome portion of this study is limited by a relatively small number of patients.

\section{Disclosure}

This work was supported by the National Institute of Neuro- logical Disorders and Stroke Hyperbaric and Normobaric Oxygen in Severe Brain Injury Grant no. R01-NS042126-03S1 (G.L.R.). Integra LifeSciences provided technical assistance and supplies related to brain tissue $\mathrm{O}_{2}$ monitoring.

Author contributions to the study and manuscript preparation include the following. Conception and design: GL Rockswold, SB Rockswold. Analysis and interpretation of data: all authors. Drafting the article: GL Rockswold, SB Rockswold. Critically revising the article: all authors. Reviewed submitted version of manuscript: all authors. Approved the final version of the manuscript on behalf of all authors: GL Rockswold. Statistical analysis: Zaun, Liu. Study supervision: GL Rockswold.

\section{Acknowledgments}

Tami Hauff provided invaluable assistance on the National Institute of Neurological Disorders and Stroke grant application and the manuscript preparation processes. Cheryl Adkinson, M.D., and her staff at the Hennepin County Medical Center provided essential services during the hyperbaric oxygen treatment sessions. Xuewei Zhang provided assistance with laboratory tests and data collection and entry into the database.

\section{References}

1. Armonda RA, Bell RS, Vo AH, Ling G, DeGraba TJ, Crandall $\mathrm{B}$, et al: Wartime traumatic cerebral vasospasm: recent review of combat casualties. Neurosurgery 59:1215-1225, 2006

2. Bauman RA, Ling G, Tong L, Januszkiewicz A, Agoston D, Delanerolle N, et al: An introductory characterization of a combat-casualty-care relevant swine model of closed head injury resulting from exposure to explosive blast. J Neurotrauma 26:841-860, 2009

3. Bayir H, Kagan VE, Tyurina YY, Tyurin V, Ruppel RA, Adelson PD, et al: Assessment of antioxidant reserves and oxidative stress in cerebrospinal fluid after severe traumatic brain injury in infants and children. Pediatr Res 51:571-578, 2002

4. Bayir H, Marion DW, Puccio AM, Wisniewski SR, Janesko KL, Clark RS, et al: Marked gender effect on lipid peroxidation after severe traumatic brain injury in adult patients. J Neurotrauma 21:1-8, 2004

5. Bouma GJ, Muizelaar JP, Choi SC, Newlon PG, Young HF: Cerebral circulation and metabolism after severe traumatic brain injury: the elusive role of ischemia. J Neurosurg 75:685-693, 1991

6. Bouma GJ, Muizelaar JP, Stringer WA, Choi SC, Fatouros P, Young HF: Ultra-early evaluation of regional cerebral blood flow in severely head-injured patients using xenon-enhanced computerized tomography. J Neurosurg 77:360-368, 1992

7. Brain Trauma Foundation: Guidelines for the management of traumatic brain injury. J Neurotrauma 24 (Suppl 1):S1S106, 2007

8. Danton GH, Dietrich WD: Inflammatory mechanisms after ischemia and stroke. J Neuropathol Exp Neurol 62:127-136, 2003

9. Daugherty WP, Levasseur JE, Sun D, Rockswold GL, Bullock MR: Effects of hyperbaric oxygen therapy on cerebral oxygenation and mitochondrial function following moderate lateral fluid-percussion injury in rats. J Neurosurg 101:499504, 2004

10. Deaton PR, McKellar CT, Culbreth R, Veal CF, Cooper JA Jr: Hyperoxia stimulates interleukin-8 release from alveolar macrophages and U937 cells: attenuation by dexamethasone. Am J Physiol 267:L187-L192, 1994

11. DeForge LE, Preston AM, Takeuchi E, Kenney J, Boxer LA, Remick DG: Regulation of interleukin 8 gene expression by oxidant stress. J Biol Chem 268:25568-25576, 1993

12. Demopoulos HB, Flamm E, Seligman M, Pietronigro DD: Oxygen free radicals in central nervous system ischemia and 
trauma, in Autor AP (ed): Pathology of Oxygen. New York: Academic Press, 1982, pp 127-155

13. Demopoulos HB, Flamm ES, Seligman ML, Pietronigro DD, Tomasula J, DeCrescito V: Further studies on free-radical pathology in the major central nervous system disorders: effect of very high doses of methylprednisolone on the functional outcome, morphology, and chemistry of experimental spinal cord impact injury. Can J Physiol Pharmacol 60:1415-1424, 1982

14. DeSalles AA, Muizelaar JP, Young HF: Hyperglycemia, cerebrospinal fluid lactic acidosis, and cerebral blood flow in severely head-injured patients. Neurosurgery 21:45-50, 1987

15. Desmarquest P, Chadelat K, Corroyer S, Cazals V, Clement A: Effect of hyperoxia on human macrophage cytokine response. Respir Med 92:951-960, 1998

16. Engström M, Polito A, Reinstrup P, Romner B, Ryding E, Ungerstedt $\mathrm{U}$, et al: Intracerebral microdialysis in severe brain trauma: the importance of catheter location. J Neurosurg 102: 460-469, 2005

17. Fam SS, Morrow JD: The isoprostanes: unique products of arachidonic acid oxidation - a review. Curr Med Chem 10: 1723-1740, 2003

18. Finkelstein EA, Corso PS, Miller TR: The Incidence and Economic Burden of Injuries in the United States. New York: Oxford University Press, 2006

19. Frykholm P, Hillered L, Langstrom B, Persson L, Valtysson J, Watanabe Y, et al: Increase of interstitial glycerol reflects the degree of ischaemic brain damage: a PET and microdialysis study in a middle cerebral artery occlusion-reperfusion primate model. J Neurol Neurosurg Psychiatry 71:455-461, 2001

20. Furuya Y, Hlatky R, Valadka AB, Diaz P, Robertson CS: Comparison of cerebral blood flow in computed tomographic hypodense areas of the brain in head-injured patients. Neurosurgery 52:340-346, 2003

21. Gossett WA, Rockswold GL, Rockswold SB, Adkinson CD, Bergman TA, Quickel RR: The safe treatment, monitoring and management of severe traumatic brain injury patients in a monoplace chamber. Undersea Hyperb Med 37:35-48, 2010

22. Harch PG, Andrews SR, Fogarty EF, Amen D, Pezzullo JC, Lucarini J, et al: A phase I study of low-pressure hyperbaric oxygen therapy for blast-induced post-concussion syndrome and post-traumatic stress disorder. J Neurotrauma 29:168185,2012

23. Ikeda Y, Long DM: The molecular basis of brain injury and brain edema: the role of oxygen free radicals. Neurosurgery 27:1-11, 1990

24. Juul N, Morris GF, Marshall SB, Marshall LF: Intracranial hypertension and cerebral perfusion pressure: influence on neurological deterioration and outcome in severe head injury. J Neurosurg 92:1-6, 2000

25. Kinoshita K, Kraydieh S, Alonso O, Hayashi N, Dietrich WD: Effect of posttraumatic hyperglycemia on contusion volume and neutrophil accumulation after moderate fluid-percussion brain injury in rats. J Neurotrauma 19:681-692, 2002

26. Klein J: Normobaric pulmonary oxygen toxicity. Anesth Analg 70:195-207, 1990

27. Krebs EG: Protein kinases. Curr Top Cell Regul 5:99-133, 1972

28. Marshall LF, Marshall SB, Klauber MR, van Berkum Clark M, Eisenberg HM, Jane JA, et al: A new classification of head injury based on computerized tomography. J Neurosurg 75 Suppl:S14-S20, 1991

29. Marshall LF, Toole BM, Bowers SA: The National Traumatic Coma Data Bank. Part 2: Patients who talk and deteriorate: implications for treatment. J Neurosurg 59:285-288, 1983

30. Maset AL, Marmarou A, Ward JD, Choi S, Lutz HA, Brooks $\mathrm{D}$, et al: Pressure-volume index in head injury. J Neurosurg 67:832-840, 1987
31. Menon DK, Coles JP, Gupta AK, Fryer TD, Smielewski P, Chatfield DA, et al: Diffusion limited oxygen delivery following head injury. Crit Care Med 32:1384-1390, 2004

32. Merenda A, Gugliotta M, Holloway R, Levasseur JE, Alessandri B, Sun D, et al: Validation of brain extracellular glycerol as an indicator of cellular membrane damage due to free radical activity after traumatic brain injury. J Neurotrauma 25:527-537, 2008

33. Metzel E,Zimmermann WE: Changes of oxygen pressure, acid-base balance, metabolites and electrolytes in cerebrospinal fluid and blood after cerebral injury. Acta Neurochir (Wien) 25:177-188, 1971

34. Miller JD, Becker DP, Ward JD, Sullivan HG, Adams WE, Rosner MJ: Significance of intracranial hypertension in severe head injury. J Neurosurg 47:503-516, 1977

35. Morrow JD: The isoprostanes: their quantification as an index of oxidant stress status in vivo. Drug Metab Rev 32:377-385, 2000

36. Muehlstedt SG, Richardson CJ, West MA, Lyte M, Rodriguez JL: Cytokines and the pathogenesis of nosocomial pneumonia. Surgery 130:602-611, 2001

37. Narayan RK, Michel ME, Ansell B, Baethmann A, Biegon A, Bracken MB, et al: Clinical trials in head injury. J Neurotrauma 19:503-557, 2002

38. Palzur E, Vlodavsky E, Mulla H, Arieli R, Feinsod M, Soustiel JF: Hyperbaric oxygen therapy for reduction of secondary brain damage in head injury: an animal model of brain contusion. J Neurotrauma 21:41-48, 2004

39. Palzur E, Zaaroor M, Vlodavsky E, Milman F, Soustiel JF: Neuroprotective effect of hyperbaric oxygen therapy in brain injury is mediated by preservation of mitochondrial membrane properties. Brain Res 1221:126-133, 2008

40. Rea GL, Rockswold GL: Barbiturate therapy in uncontrolled intracranial hypertension. Neurosurgery 12:401-404, 1983

41. Rockswold GL, Ford SE, Anderson DC, Bergman TA, Sherman RE: Results of a prospective randomized trial for treatment of severely brain-injured patients with hyperbaric oxygen. J Neurosurg 76:929-934, 1992

42. Rockswold GL, Ford SE, Anderson JR, Blanchfield E: Patient monitoring in the monoplace hyperbaric chamber. Hyperbaric Oxygen Review 6:161-168, 1985

43. Rockswold GL, Leonard PR, Nagib MG: Analysis of management in thirty-three closed head injury patients who "talked and deteriorated." Neurosurgery 21:51-55, 1987

44. Rockswold SB, Rockswold GL, Vargo JM, Erickson CA, Sutton RL, Bergman TA, et al: Effects of hyperbaric oxygenation therapy on cerebral metabolism and intracranial pressure in severely brain injured patients. J Neurosurg 94:403-411, 2001

45. Rockswold SB, Rockswold GL, Zaun DA, Zhang X, Cerra CE, Bergman TA, et al: A prospective, randomized clinical trial to compare the effect of hyperbaric to normobaric hyperoxia on cerebral metabolism, intracranial pressure, and oxygen toxicity in severe traumatic brain injury. Clinical article. J Neurosurg 112:1080-1094, 2010

46. Rogatsky GG, Kamenir Y, Mayevsky A: Effect of hyperbaric oxygenation on intracranial pressure elevation rate in rats during the early phase of severe traumatic brain injury. Brain Res 1047:131-136, 2005

47. Siesjö BK, Siesjö P: Mechanisms of secondary brain injury. Eur J Anaesthesiol 13:247-268, 1996

48. Simard JM, Kahle KT, Gerzanich V: Molecular mechanisms of microvascular failure in central nervous system injurysynergistic roles of NKCC1 and SUR1/TRPM4. A review. J Neurosurg 113:622-629, 2010

49. Simard JM, Kilbourne M, Tsymbalyuk O, Tosun C, Caridi J, Ivanova $S$, et al: Key role of sulfonylurea receptor 1 in progressive secondary hemorrhage after brain contusion. J Neurotrauma 26:2257-2267, 2009

50. Soustiel JF, Palzur E, Vlodavsky E, Veenman L, Gavish M: 
The effect of oxygenation level on cerebral post-traumatic apoptotsis is modulated by the $18-\mathrm{kDa}$ translocator protein (also known as peripheral-type benzodiazepine receptor) in a rat model of cortical contusion. Neuropathol Appl Neurobiol 34:412-423, 2008

51. Ståhl N, Mellergård P, Hallström A, Ungerstedt U, Nordström $\mathrm{CH}$ : Intracerebral microdialysis and bedside biochemical analysis in patients with fatal traumatic brain lesions. Acta Anaesthesiol Scand 45:977-985, 2001

52. Tisdall MM, Tachtsidis I, Leung TS, Elwell CE, Smith M: Increase in cerebral aerobic metabolism by normobaric hyperoxia after traumatic brain injury. J Neurosurg 109:424-432, 2008

53. Tolias CM, Reinert M, Seiler R, Gilman C, Scharf A, Bullock MR: Normobaric hyperoxia-induced improvement in cerebral metabolism and reduction in intracranial pressure in patients with severe head injury: a prospective historical cohortmatched study. J Neurosurg 101:435-444, 2004

54. Valadka AB, Goodman JC, Gopinath SP, Uzura M, Robertson CS: Comparison of brain tissue oxygen tension to microdialysis-based measures of cerebral ischemia in fatally headinjured humans. J Neurotrauma 15:509-519, 1998

55. van den Brink WA, van Santbrink H, Steyerberg EW, Avezaat CJ, Suazo JA, Hogesteeger C, et al: Brain oxygen tension in severe head injury. Neurosurgery 46:868-878, 2000

56. Vespa PM, O'Phelan K, McArthur D, Miller C, Eliseo M, Hirt $\mathrm{D}$, et al: Pericontusional brain tissue exhibits persistent elevation of lactate/pyruvate ratio independent of cerebral perfusion pressure. Crit Care Med 35:1153-1160, 2007

57. Vigué B, Ract C, Benayed M, Zlotine N, Leblanc PE, Samii $\mathrm{K}$, et al: Early SjvO2 monitoring in patients with severe brain trauma. Intensive Care Med 25:445-451, 1999

58. Vlodavsky E, Palzur E, Feinsod M, Soustiel JF: Evaluation of the apoptosis-related proteins of the BCL-2 family in the traumatic penumbra area of the rat model of cerebral contusion, treated by hyperbaric oxygen therapy: a quantitative immunohistochemical study. Acta Neuropathol 110:120-126, 2005
59. Vlodavsky E, Palzur E, Soustiel JF: Hyperbaric oxygen therapy reduces neuroinflammation and expression of matrix metalloproteinase-9 in the rat model of traumatic brain injury. Neuropathol Appl Neurobiol 32:40-50, 2006

60. Wada K, Ito M, Miyazawa T, Katoh H, Nawashiro H, Shima $\mathrm{K}$, et al: Repeated hyperbaric oxygen induces ischemic tolerance in gerbil hippocampus. Brain Res 740:15-20, 1996

61. Wada K, Miyazawa T, Nomura N, Tsuzuki N, Nawashiro H, Shima K: Preferential conditions for and possible mechanisms of induction of ischemic tolerance by repeated hyperbaric oxygenation in gerbil hippocampus. Neurosurgery 49:160-167, 2001

62. Wilson JT, Pettigrew LE, Teasdale GM: Structured interviews for the Glasgow Outcome Scale and the extended Glasgow Outcome Scale: guidelines for their use. J Neurotrauma 15:573585,1998

63. Zhang T, Yang QW, Wang SN, Wang JZ, Wang Q, Wang Y, et al: Hyperbaric oxygen therapy improves neurogenesis and brain blood supply in piriform cortex in rats with vascular dementia. Brain Inj 24:1350-1357, 2010

64. Zhuang J, Shackford SR, Schmoker JD, Anderson ML: The association of leukocytes with secondary brain injury. J Trauma 35:415-422, 1993

65. Zhou Z, Daugherty WP, Sun D, Levasseur JE, Altememi N, Hamm RJ, et al: Protection of mitochondrial function and improvement in cognitive recovery in rats treated with hyperbaric oxygen following lateral fluid-percussion injury. J Neurosurg 106:687-694, 2007

Manuscript submitted July 27, 2012.

Accepted February 4, 2013.

Please include this information when citing this paper: published online March 19, 2013; DOI: 10.3171/2013.2.JNS121468.

Address correspondence to: Gaylan L. Rockswold, M.D., Ph.D., Hennepin County Medical Center, 701 Park Avenue, Minneapolis, Minnesota 55415. email: gaylan.rockswold@hcmed.org. 